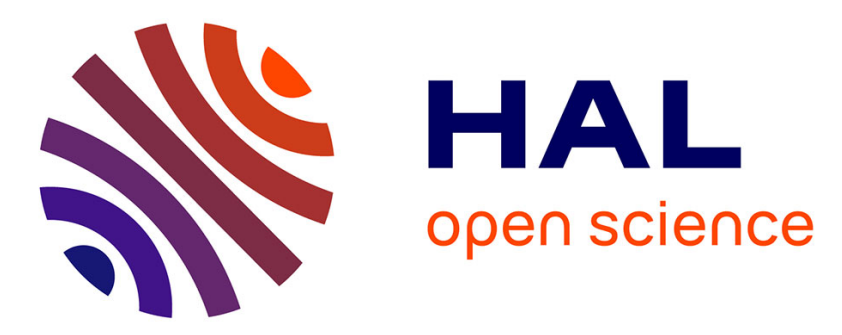

\title{
A novel method for soil quality in life cycle assessment using several soil indicators
}

\author{
Oberholzer, Freiermuth Knuchel, Weisskopf, Gaillard
}

\section{To cite this version:}

Oberholzer, Freiermuth Knuchel, Weisskopf, Gaillard. A novel method for soil quality in life cycle assessment using several soil indicators. Agronomy for Sustainable Development, 2012, 32 (3), pp.639649. 10.1007/s13593-011-0072-7 . hal-00930549

\section{HAL Id: hal-00930549 \\ https://hal.science/hal-00930549}

Submitted on 1 Jan 2012

HAL is a multi-disciplinary open access archive for the deposit and dissemination of scientific research documents, whether they are published or not. The documents may come from teaching and research institutions in France or abroad, or from public or private research centers.
L'archive ouverte pluridisciplinaire HAL, est destinée au dépôt et à la diffusion de documents scientifiques de niveau recherche, publiés ou non, émanant des établissements d'enseignement et de recherche français ou étrangers, des laboratoires publics ou privés. 


\title{
A novel method for soil quality in life cycle assessment using several soil indicators
}

\author{
Hans-Rudolf Oberholzer • Ruth Freiermuth Knuchel • \\ Peter Weisskopf • Gérard Gaillard
}

Accepted: 2 December 2011 / Published online: 12 January 2012

(C) INRA and Springer-Verlag, France 2012

\begin{abstract}
Soil quality is recognised as being a key parameter of sustainable agricultural management. Existing methods of life cycle impact assessment (LCIA) do not include any soil quality indicators other than soil organic matter content. This paper rectifies this omission by presenting Swiss Agricultural Life Cycle Assessment for Soil Quality (SALCA-SQ), a LCIA conform method, to assess effects of agricultural management practices on soil quality. SALCASQ characterises all major types of impacts of land management practices on the quality of arable soils by means of nine indicators covering soil physical, chemical and biological aspects: rooting depth of soil, macropore volume, aggregate stability, organic carbon content, heavy metal content, organic pollutants, earthworm biomass, microbial biomass and microbial activity. Since these indicators are not measured directly, the impacts of agricultural management activities are assessed via impact class modelling to determine the most probable changes in soil quality indicators as a result of on-farm agricultural practices. To illustrate the application and results of SALCA-SQ, treatment effects of a long-term field trial on soil quality were assessed and compared against measured field data. The data generated by SALCA-SQ revealed the important influence of fertiliser regime on soil quality. Field measurements generally confirmed SALCA-SQ assessments, but small differences between measured data in different treatments could not be predicted. Case studies on theoretical scenarios covering a broad spectrum of site conditions and management practices demonstrated the potential of SALCA-SQ to assess the
\end{abstract}

H.-R. Oberholzer $(\bowtie) \cdot$ R. Freiermuth Knuchel $•$ P. Weisskopf $\cdot$ G. Gaillard

Agroscope Reckenholz-Tänikon Research Station ART,

Reckenholzstrasse 191,

8046 Zürich, Switzerland

e-mail: hansrudolf.oberholzer@art.admin.ch effects of the major impact classes on the nine soil quality indicators, thus giving a refined picture of the potential effects of a farming system on soil quality. In principle, these results support the assumption that SALCA-SQ has the potential to assess effects of agricultural management practices on soil quality, but validity in a strict scientific sense remains to be substantiated. In addition, SALCA-SQ can be used by agricultural advisory services and farmers to analyse agricultural management effects on soil quality and move soil management in a more sustainable direction.

Keywords SALCA-SQ - Land use - Life cycle impact assessment (LCIA) · Soil quality

\section{Introduction}

Large areas of arable soil are used for agricultural production worldwide. Soil degradation is a serious problem in Europe, with agricultural practices recognised as having a negative impact, preventing the soil from performing its broad range of functions and services to humans and ecosystems (EU Commission 2006). In order to ensure sustainability, it is therefore important to minimise impacts of land use on soil quality. Life cycle assessment (LCA) has been proven to be a suitable methodology for assessing the environmental impacts of agricultural production in general (Audsley et al. 1997; Brentrup 2003; Gaillard and Nemecek 2009). Since LCA methodology was first developed for industrial products and processes, its focus was on impacts such as energy demand, global warming potential or eutrophication, while impacts on soil quality were not considered. Udo de Haes et al. (2002) provided the first comprehensive review of existing land use impact assessment methods, while Guinée et al. (2006) grouped them into 
single and multiple indicator impact assessment methods. Milà i Canals (2003) described an example of a single indicator method for the agricultural sector that uses the change in soil organic matter as a key parameter for soil quality. In contrast, Peters et al. (2003) proposed a method with 17 different indicators grouped into four aspects: soil, water, vegetation and biodiversity. Unfortunately, none of these methods fulfils the major expectation in LCA of agricultural systems that differences between the impacts of different agricultural management options ('inventory items') on soil quality should be visible in the results. Furthermore, the existing methods are often too general, and most of them are not operational (Guinée et al. 2006).

Jolliet et al. (2004) emphasised the site dependency of damaging land use effects and raised the possibility of developing either a midpoint approach, reporting effects on soil quality and biodiversity separately, or an endpoint approach, directly expressing the effects at the level of the damage category 'biotic or abiotic natural environment'. The degree of biodiversity (existence value), the biotic production potential (including soil fertility in a narrow sense) and the soil quality are currently seen as the three impact pathways of land use (Milà i Canals et al. 2006). Due to the lack of a widely accepted methodology (Milà i Canals et al. 2006), an interdisciplinary research team at Agroscope Reckenholz-Tänikon Research Station (ART) has developed an operational impact assessment method for soil quality called Swiss Agricultural Life Cycle Assessment for Soil Quality (SALCA-SQ). This multi-indicator midpoint approach combines expert knowledge about soil science and LCA based on arable farming practices in Switzerland. In particular, it allows the effects of different agricultural management practices and different intensities of the same management practices to be considered. Therefore, SALCASQ requires detailed information on agricultural management practices, but allows for a differentiated assessment of management effects on soil quality. The results of the assessment are intended for use in advising farmers to adapt their management practices in order to maintain or even enhance soil quality, and thereby sustainability.

Currently, definitions of soil quality are based on the interaction of soil functions and soil properties in an ecological context (Benedetti et al. 2000; Schjønning et al. 2004). The background for SALCA-SQ is the more comprehensive definition of soil quality by Karlen et al. (1997) as "...the capacity of a specific kind of soil to function within natural or managed ecosystem boundaries, to sustain plant and animal productivity, maintain or enhance water and air quality, and support human health and habitation".

This definition corresponds to the 'ecological soil quality' referred to by Milà i Canals et al. (2006) and was used as basis for the method development. Overall, soil quality cannot be measured directly, and thus it can only be inferred from an array of measured indicator values (Nortcliff 2002). A number of studies have proposed different indicators of soil quality, each covering certain aspects depending upon its focus and the feasibility of data collection (Doran and Parkin 1996; Harris et al. 1996; Karlen et al. 1998; Nielsen and Winding 2002; Breure et al. 2003; Oberholzer and Höper 2007).

In this paper, the SALCA-SQ method is presented and explained. Results of its application on different treatments of a long-term field trial are shown as an example of use and are compared against real data measured in this field trial. In order to test the plausibility of SALCA-SQ assessments, scenarios with generic inventories were also tested.

\section{Materials and methods}

The SALCA-SQ method was developed to assess the impact of agricultural soil use on soil quality in arable regions with temperate climate in central Europe. According to defined criteria, we chose relevant soil properties from published indicator sets in order to assess medium-term impacts of agricultural practices that are non-reversible within the period of a typical crop rotation, i.e. 5-7 years. The selection criteria reflected ISO standard 14044 (ISO 2006) and included the following requirements:

(a) The category indicator (i.e. soil properties) has to be environmentally relevant, which means that a direct relationship to soil functions is required.

(b) The indicator must be able to reflect the consequences of the life cycle inventory (LCI) results on the category endpoint(s) at least qualitatively.

(c) The characterisation model for each category indicator must be scientifically and technically valid and based upon a distinct identifiable environmental mechanism and/or reproducible empirical observations.

(d) The appropriateness of the characterisation model used for deriving the indicator in the context of the goal and scope of the study must be explained for an agricultural context.

(e) Soil characteristics that can be changed by typical agricultural activities within a year are not suitable indicators, i.e. an indicator value should be irreversible at least in the medium-term time horizon of a crop rotation.

On applying this list of criteria, the nine soil indicators presented in Fig. 1 were chosen for SALCA-SQ. These comprise a set of indicators that allows soil quality to be comprehensively assessed. Since in typical life cycle impact assessment (LCIA) studies these indicators cannot be measured on-site, it is necessary to evaluate them by modelling the impact pathway between the inventory data (management practices) and each of the nine soil quality indicators 


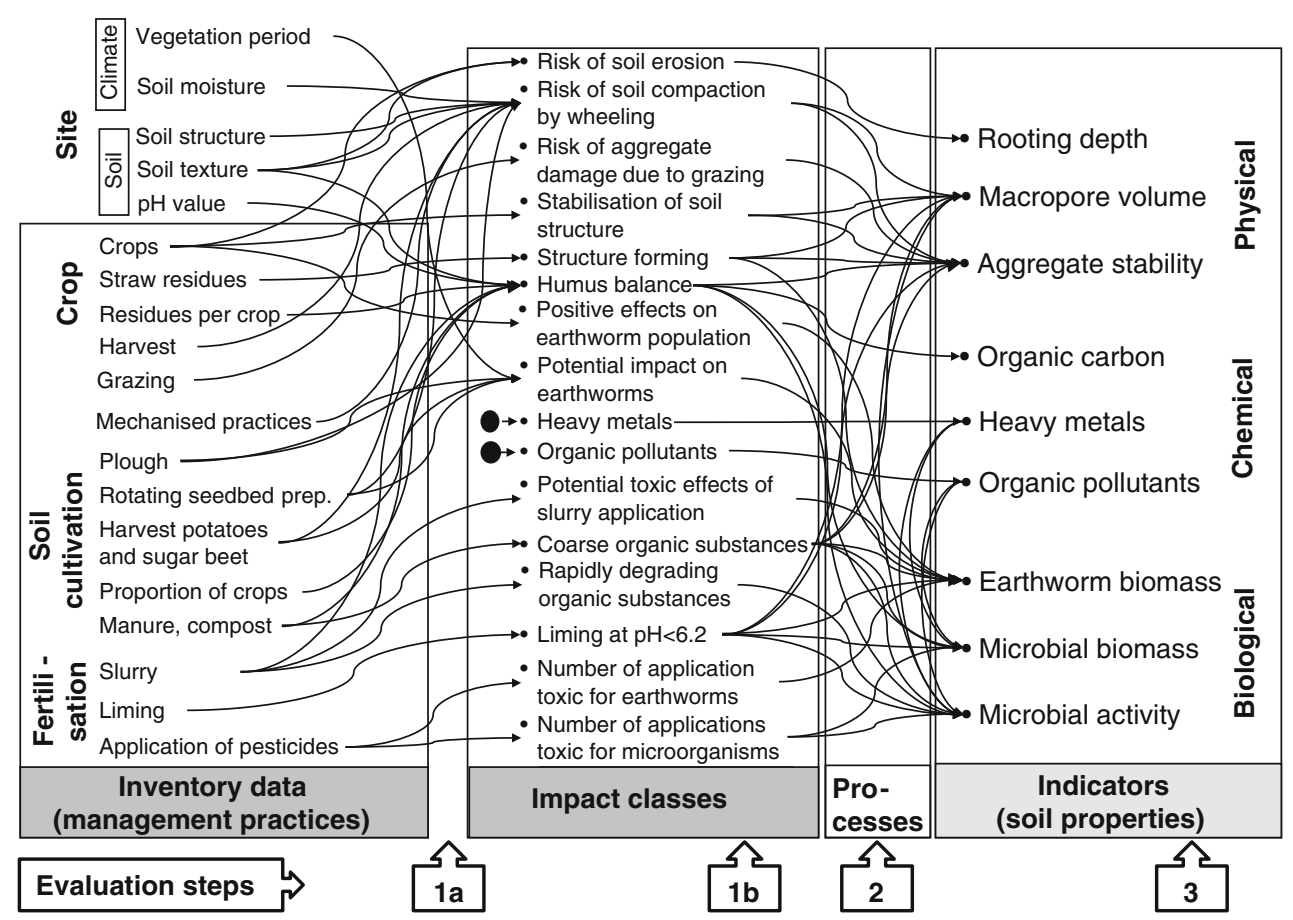

Fig. 1 Illustration of the procedure to assess the effects of agricultural management practices (inventory data) on soil quality indicators. The different management practices listed in the life cycle inventory exert an effect on the indicators of soil quality via a number of impact classes. The specific effects of management practices on impact classes are first of all allocated (step 1a) and then evaluated (step 1b). For every indicator, the evaluations of all the impact classes are weighed

(soil properties). The following characteristics are typical for SALCA-SQ impact assessment modelling:

1. Quantitative description of management practices requires the extension of the common inventory datasets describing agricultural management practices. Farmers must document not only their management activities regarding soil tillage, sowing, fertiliser application, plant protection, cultivation measures and harvest processes but also management decisions such as the choice of main and cover crops, as well as the use of temporary leys in the crop rotation.

2. Relations between management inventory data and soil quality indicators are complex, highly non-linear, interactive and often not quantifiable with current knowledge.

3. In a direct on-site soil quality assessment, the absolute value of soil quality indicators (soil properties) can be measured, but in LCIA, we do not know the absolute value of any indicator because the initial state of soil quality in a given case is unknown, so we can only assess changes in soil quality as relative changes of indicator values caused by impact classes.

Impact assessment modelling using SALCA-SQ does not intend to determine absolute values of soil quality according to their relevance and summed up (step 2). Finally, the sum of effects of all the relevant impact classes on a single soil quality indicator is assessed (step 3). The steps in the evaluation process are described in detail in the text. Black circles indicate that heavy metals and organic pollutants are evaluated in a separate SALCA method and that these results are inserted into SALCA-SQ at this point

indicators, but rather to assess the change in indicator values due to agricultural management activities under the given site conditions. Consequently, the impact assessment determines how the value of an indicator is likely to change as a result of agricultural practices (i.e. whether there is a trend towards improvement or towards impairment).

\subsection{Description of impact classes and their evaluation}

In a first step, all positive and negative effects on the different impact classes that could be triggered by the given management practices are identified in detail (Fig. 1, step 1a; Table 1). Similar effects of other management practices are added for each impact class (step 1b). The risk of soil erosion is estimated quantitatively and influences the rooting depth of a soil. The threshold for an impact according to the Swiss ordinance on impacts on soils (OIS 1998) is indicated in Table 1. The risk of soil compaction by wheeling is estimated by a semi-quantitative method, whereby the percentage of wheeled soil area with a compaction risk is assessed. Quality indicators affected are macropore volume and aggregate stability. The risk of aggregate damage due to grazing is estimated based on soil moisture at the time of grazing. The direct contribution of the individual crops in a 


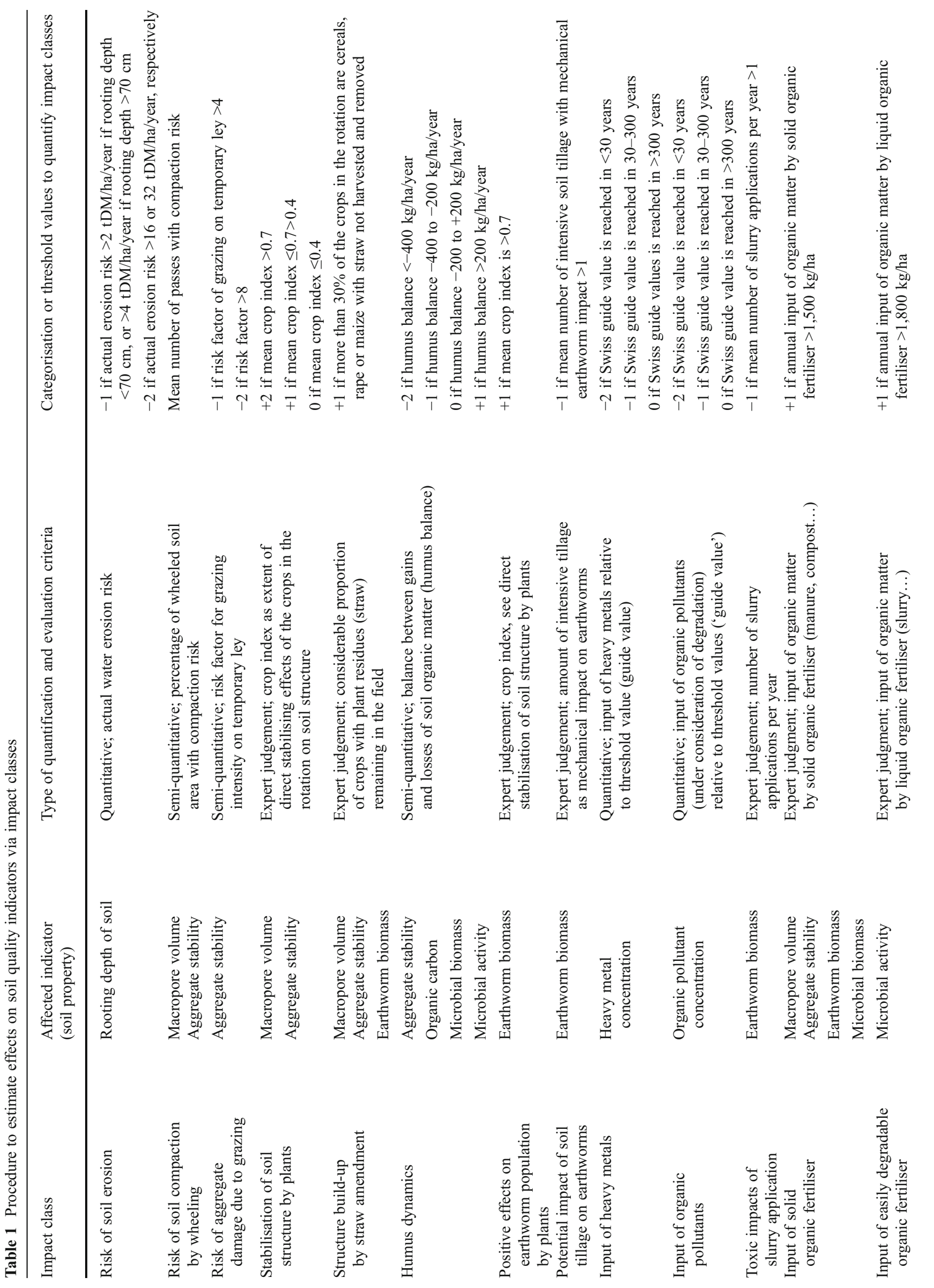


crop rotation to stabilisation of soil structure is estimated by considering intensity and duration of rooting and soil cover and is expressed as individual crop index on a scale from 0 to 1 . The contribution of all crops in a crop rotation to the direct stabilisation of soil structure is calculated as crop index, the mean value of the individual index of all crops. An additional positive contribution to the development of soil structure by biological processes is expected if plant residues of cereals, rape or maize are left in the field on more than $30 \%$ of the total area. A humus balance, a simple method considering carbon mineralisation and carbon inputs by crop residues and organic fertilisers, is calculated to estimate the effect of management on soil organic matter content. The crop index is used to assess direct effects of crops on the stabilisation of soil structure and, in addition, to estimate their positive effects on earthworm populations by their contribution to favourable living (and feeding) conditions. On the other hand, the number of intensive soil tillage practices is recorded in order to detect negative effects on earthworms. The input of heavy metals and the net input (input minus mineralisation) of organic pollutants are included as impact classes for the concentration of heavy metals and organic pollutants in soils. Both are calculated by a separate SALCA method (Freiermuth 2006) and the results inserted in SALCA-SQ. The number of slurry applications is determined to estimate possible toxic effects of liquid manure on earthworm populations. The application of solid organic fertiliser is recorded as a positive impact class for several indicators if it exceeds the amount corresponding to the formation of 1.4 livestock units (LU), corresponding to an input of $1,500 \mathrm{~kg} / \mathrm{ha}$. In the same way, the application of liquid organic fertiliser with easily degradable organic substances is used as a measure of the improvement in biological activity in soils. Liming of soils with a $\mathrm{pH}$ value below 6.2 is recorded as a positive impact class for several indicators. Applications of pesticides that are toxic for earthworms or soil microorganisms are counted as negative impact classes. In the last row of Table 1 , the range of evaluation results for all impact classes is given either as a categorisation $(-2,-1,0,+1$ or +2$)$ or as a quantification (Fig. 1, step 1b).

\subsection{Aggregation of the effects of relevant impact classes on single soil quality indicators}

After quantifying the effects of the management practices on the impact classes, the combined effect of all impact classes influencing an individual soil quality indicator is determined by weighing and summing up all contributions of the relevant impact classes (Fig. 1, step 2). The soil quality indicator rooting depth is dependent on the impact class 'soil erosion' alone. Macropore volume can be negatively influenced by 'risk of soil compaction by wheeling', but 
positively by 'stabilisation of soil structure by plants' (expressed as crop index) and to a lesser extent by 'structure build-up by straw amendment', 'input of solid organic fertiliser' and 'liming at $\mathrm{pH}<6.2$ '. Aggregate stability is influenced by the same impact classes as macropore volume and by additional two impact classes, 'risk of aggregate damage due to grazing' and 'humus dynamics'. Influences on organic carbon are calculated by means of a humus balance method, taking into account carbon mineralisation and additions of organic carbon by crop residues and organic fertiliser (equal to impact class 'humus dynamics'). Impacts on the two soil quality indicators heavy metals and organic pollutants are calculated based on the inputs of those substances by management practices and, in the case of organic pollutants, possible degradation, and are categorised according to the amount of input relative to the acceptable threshold value (guide value) as indicated in the Swiss ordinance on impacts on soils (OIS 1998). Earthworm biomass may be reduced by the impact classes 'potential impact of soil tillage on earthworms', 'toxic impacts of slurry application' and 'number of pesticide applications with toxic effects on earthworms', but can be promoted by the impact classes 'positive effects on earthworm populations by plants', 'input of solid organic fertiliser' and 'liming at $\mathrm{pH}<6.2$ '. The two soil microbiological soil quality indicators (microbial biomass and microbial activity) may be adversely affected by the soil quality indicators 'heavy metal concentration', 'organic pollutant concentration' and 'macropore volume', as well as by the impact class 'number of pesticide applications with toxic effects on microorganisms'. On the other hand, they can be improved by the indicator organic carbon and the impact classes 'liming at $\mathrm{pH}<6.2$ ' and 'input of organic matter', and microbial activity especially by 'input of easily degradable organic fertiliser'. All these effects of the different impact classes on a soil quality indicator are visualised in Fig. 1 by the box called 'processes'.

\subsection{Assessment of individual indicators and soil quality as a whole}

The aggregated effects of the different impact classes per soil quality indicator are calculated by weighing and summing up the individual effects (Fig. 1, step 2). In order to assess the total sum of effects of the impact classes on a single soil quality indicator, an interpretation scheme was developed which uses the following five categories: highly unfavourable $(--)$, unfavourable $(-)$, none $(0)$, favourable $(+)$ and highly favourable $(++)$ (Fig. 1, step 3$)$.

Soil quality cannot simply be represented by the total sum of effects on all indicators because soil functions may be limited by each individual indicator, e.g. more active soil microorganisms cannot compensate for reduced rooting depth of soil. Therefore, a threat to soil quality is assumed as soon as one single indicator is adversely affected. Furthermore, the assessment of individual soil quality indicators is helpful for the improvement of management practices because unwanted effects of management practices that have been identified by SALCA-SQ can easily be traced back.

\subsection{Practical aspects}

The typical 5- to 7-year duration of a crop rotation was chosen as the appropriate timeframe for assessments of management effects on soil quality. This allows for the assessment of impacts on slowly changing soil properties, but does not consider short-term changes that are reversible by a single management practice. Since it can generally be assumed that the management of all the fields on a farm during a single year reflects the management of an individual field during the whole crop rotation period (e.g. Cowell and Clift 2000), it is possible to apply SALCA-SQ on farm level with data collected for a single year. For practical purposes, a tool was developed using Microsoft ${ }^{\circledR}$ Excel to perform the calculations from input tables (with inventory and site data) to the final result (assessment per soil quality indicator for the whole farm).

\subsection{Application of SALCA-SQ method}

Data from the long-term DOC (dynamic, organic, conventional management systems) field trial near Basle, Switzerland (Nemecek et al. 2010a, b), are used here to illustrate the application of SALCA-SQ. The DOC experiment was started in 1978 to compare the consequences of bio-organic, biodynamic and conventional farming systems on agronomic and ecological characteristics of farms (Fließbach et al. 2007).

For the case study, we chose management data from 1985 to 1998 (13 years), i.e. from the second and third crop rotations of the DOC field trial. The following five treatments were compared: organic farming with stacked farmyard manure and slurry (BIOORG); bio-dynamic farming with composted farmyard manure and slurry (BIODYN); conventional farming with fresh farmyard manure, slurry and mineral fertiliser (CONFYM); conventional farming with exclusively mineral fertiliser after 1 crop rotation without fertilisation (CONMIN); and bio-dynamic farming without fertilisation (NOFERT). Each management system was applied in four replicates to three subplots with different crops, corresponding to different positions in the same crop rotation. The amount of fertiliser applied corresponded to 1.4 LU per hectare. The 7-year crop rotation consisted of potatoes, winter wheat ( 2 years), sugar beet, winter barley, grass-clover ley (temporary, 2 years), cover crop and a catch crop (which was harvested). In the third crop rotation, 
winter barley was replaced by a third year of temporary grass-clover ley.

In order to test the plausibility of SALCA-SQ assessments, scenarios with generic inventories were tested, covering different crop rotations, different types of machinery (standard and heavy) and different combinations of site conditions, namely loamy soil and standard climate and clayey soil and wet climate. Crop rotations were $\mathrm{CR} 1=$ monocropped maize; $\mathrm{CR} 2=2$ winter cereals, rape, potato and 2 years ley; and $\mathrm{CR} 3=3$ winter cereals, 2 times rape and 1 sugar beet. $\mathrm{F} 1=$ mineral fertiliser, F2=manure and slurry equivalent to $1 \mathrm{LU}$ and F3=manure and slurry equivalent to $1.8 \mathrm{LU}$.

\section{Results and discussion}

The results from SALCA-SQ and actual measured parameters in the DOC field trial are shown in Table 2. The SALCA-SQ results for all subplots of each treatment and the entire 13-year period indicated negative effects of CONMIN and NOFERT on soil quality, whereas results for BIOORG, BIODYN and CONFYM suggested positive effects. These results are mainly influenced by fertiliser regime, demonstrating the importance of this parameter for maintaining soil quality. Differing effects of the treatments in the DOC field trial on soil quality indicators were mainly due to the use of organic fertilisers because other important management aspects such as crop rotation and soil tillage were identical or nearly identical for all DOC treatments. The highly negative impact of the two DOC treatments without organic manure (CONMIN and NOFERT) on soil organic carbon predicted by SALCA-SQ was confirmed by field measurements, which showed a significant decrease in soil organic matter content (Fließbach et al. 2007). However, the predicted positive trend for soil organic carbon in the other three treatments was not supported by field data. The negative values predicted for aggregate stability in the CONMIN and NOFERT systems were a consequence of those for organic carbon, an important factor influencing aggregate stability. SALCA-SQ predictions of trends for aggregate stability in the DOC field trial (Table 2) were generally in accordance with measurements of aggregate stability, although the reduction in aggregate stability in the CONFYM treatment was not predicted. In fact, measured data indicated that there was no clear correlation between aggregate stability and carbon content in this treatment, in contrast to the basic assumptions of SALCA-SQ. Rooting depth was not affected by the DOC treatments because erosion processes were irrelevant under the site conditions of the DOC field trial site (field plots situated on a plain). The indicators macropore volume and

Table 2 Case study: Assessment of treatment effects on soil quality indicators calculated by SALCA-SQ (Nemecek et al. 2010a) and measured results for a number of soil properties in the DOC field experiment

\begin{tabular}{|c|c|c|c|c|c|}
\hline Indicator & BIOORG & BIODYN & CONFYM & CONMIN & NOFERT \\
\hline Rooting depth of soil & 0 & 0 & 0 & 0 & 0 \\
\hline Macropore volume & 0 & 0 & 0 & 0 & 0 \\
\hline Aggregate stability & + & + & + & - & - \\
\hline Organic carbon & + & + & + & -- & -- \\
\hline Heavy metal content & 0 & 0 & 0 & 0 & 0 \\
\hline Organic pollutants & 0 & 0 & 0 & 0 & 0 \\
\hline Earthworm biomass & 0 & 0 & 0 & 0 & 0 \\
\hline Microbial biomass & + & + & + & - & - \\
\hline Microbial activity & + & + & + & - & - \\
\hline Macropore volume ${ }^{a}$ & $8.9 \mathrm{a}$ & $10.1 \mathrm{a}$ & $8.2 \mathrm{a}$ & $9.0 \mathrm{a}$ & $8.8 \mathrm{a}$ \\
\hline Aggregate stability ${ }^{a}$ & $0.66 \mathrm{ab}$ & $0.63 \mathrm{~b}$ & $0.69 \mathrm{a}$ & $0.68 \mathrm{ab}$ & $0.66 \mathrm{ab}$ \\
\hline Soil organic carbon content ${ }^{\mathrm{b}}$ & $12.8 \mathrm{ab}$ & $13.9 \mathrm{a}$ & $12.4 \mathrm{ab}$ & $11.0 \mathrm{~b}$ & $9.8 \mathrm{c}$ \\
\hline Earthworm biomass $^{\mathrm{c}}$ & $180 \mathrm{ab}$ & $183 \mathrm{ab}$ & $205 \mathrm{a}$ & $166 \mathrm{~b}$ & $142 \mathrm{~b}$ \\
\hline Microbial biomass (SIR) ${ }^{\mathrm{b}}$ & $384 \mathrm{a}$ & $422 \mathrm{a}$ & $390 \mathrm{a}$ & $315 \mathrm{~b}$ & $246 \mathrm{c}$ \\
\hline Microbial biomass (FEC) ${ }^{\mathrm{b}}$ & $389 \mathrm{~b}$ & $440 \mathrm{a}$ & $359 \mathrm{~b}$ & $272 \mathrm{c}$ & $223 \mathrm{~d}$ \\
\hline Microbial activity: soil respiration ${ }^{\mathrm{b}}$ & $0.37 \mathrm{a}$ & $0.38 \mathrm{a}$ & $0.37 \mathrm{a}$ & $0.37 \mathrm{a}$ & $0.27 \mathrm{~b}$ \\
\hline
\end{tabular}

SALCA-SQ assessments: mean results for all subplots over the entire 13-year experimental period, expressed as $--=$ highly unfavourable, $-=$ unfavourable, $0=$ none,$+=$ favourable and $++=$ highly favourable. See text for explanation of DOC treatments and abbreviations used

Values within rows with different letters are significantly different according to ANOVA and post hoc Tukey test $(p<0.05)$

${ }^{a}$ Measured data from Zihlmann (unpublished results)

${ }^{\mathrm{b}}$ Measured data from Oberholzer et al (2009)

${ }^{\mathrm{c}}$ Measured data from Jossi et al. (2007) 
aggregate stability could not have been influenced differently by agricultural traffic because all treatments were managed in the same way using small, lightweight machinery. In order to deal with the lack of machinery data for SALCA-SQ, we implemented a data set characterising machinery, operation dates and site conditions typical for practical farm situations in Switzerland. When this data set was applied on DOC treatments, SALCA-SQ did not predict any trend in the 13-year changes in the indicator macropore volume. The results for the two indicators heavy metal content and organic pollutants did not differ between the treatments. According to the SALCASQ results, the input of heavy metals and organic pollutants in all treatments had no impacts on soil quality. Although no analytical field data were available for heavy metals and organic pollutants, these assessments can be assumed to be correct because no fertilisers or pesticides containing critical amounts of these substances were used since the start of the DOC field experiment.

SALCA-SQ did not indicate any differences between the effects of the three farming systems with organic fertilisers (BIOORG, BIODYN and CONFYM) on soil microbiological indicators, which was more or less supported by measured soil microbial biomass and soil respiration. SALCA-SQ predicted a negative impact on these indicators by CONMIN and NOFERT, an assessment supported by all field measurements, which showed significant differences between the treatments with or without organic fertilisers.

Examples of the plausibility tests conducted on SALCASQ assessments are presented in Table 3. For all situations with mineral fertiliser and straw removal, SALCA-SQ assumes negative effects on the indicators (carbon content, aggregate stability, microbial biomass and microbial activity).

According to SALCA-SQ assessments, heavy machinery had additional impacts on the indicator macropore volume under both standard and wet climate conditions. These effects may be the result of specific interactions between field operations (date and machinery used) and climate conditions. For example, the indicators macropore volume and aggregate stability were only affected under wet conditions for fertilisation system 2 due to wheeling for manure application. For crop rotation CR2, SALCA-SQ assumed a positive trend for the indicators carbon content and aggregate stability for both standard and wet conditions, notably because of the 2-year ley combined with organic fertilisation. The impact of the generic test inventories on the earthworm indicators under wet climate conditions, as predicted by SALCA-SQ, is caused by the direct effects of soil tillage (ploughing) on earthworms; this interaction, soil tillage $\times$ operation date $\times$ climate, is due to the implementation of earthworm susceptibility depending on the depth of
Table 3 Plausibility test: SALCA-SQ assessments of different scenarios regarding crop rotation $(\mathrm{CR})$, fertiliser $(\mathrm{F})$, climate (standard and wet) and machinery $(\mathrm{M} 1=$ standard, M2=heavy)
SALCA-SQ assessments expressed as $--=$ highly unfavourable, $-=$ unfavourable, $0=$ none,$+=$ favourable and $++=$ highly favourable. CR1 $=$ monocropped maize; CR2 $=2$ winter cereals, rape, potato and 2-year ley; and CR3 =3 winter cereals, 2 times rape and 1 sugar beet. $\mathrm{F} 1=$ mineral fertiliser, $\mathrm{F} 2=$ manure and slurry equivalent to 1 livestock unit (LU) and F3= manure and slurry equivalent to $1.8 \mathrm{LU}$

\begin{tabular}{|c|c|c|c|c|c|c|c|c|}
\hline \multirow[b]{2}{*}{ Soil quality indicator } & \multicolumn{3}{|l|}{ CR1 } & \multicolumn{2}{|l|}{ CR2 } & \multicolumn{3}{|c|}{ CR3 } \\
\hline & D2, M1 & D2, M2 & D6 & D2 & D6 & $\mathrm{D} 2$ & D6 & D8 \\
\hline \multicolumn{9}{|c|}{ Standard climate conditions } \\
\hline Rooting depth & 0 & 0 & 0 & 0 & 0 & 0 & 0 & 0 \\
\hline Macropore volume & 0 & - & 0 & 0 & 0 & 0 & 0 & 0 \\
\hline Aggregate stability & - & -- & 0 & - & + & - & 0 & + \\
\hline Carbon content & -- & -- & 0 & -- & + & -- & 0 & + \\
\hline Heavy metal content & 0 & 0 & 0 & 0 & 0 & 0 & 0 & 0 \\
\hline Organic pollutants & 0 & 0 & 0 & 0 & 0 & 0 & 0 & 0 \\
\hline Earthworm biomass & 0 & 0 & 0 & 0 & 0 & - & - & 0 \\
\hline Microbial biomass & - & - & 0 & - & 0 & - & 0 & + \\
\hline Microbial activity & - & - & 0 & - & 0 & - & 0 & + \\
\hline \multicolumn{9}{|l|}{ Wet climate conditions } \\
\hline Rooting depth & 0 & 0 & 0 & 0 & 0 & 0 & 0 & 0 \\
\hline Macropore volume & 0 & - & - & 0 & 0 & 0 & 0 & 0 \\
\hline Aggregate stability & - & -- & - & - & + & - & 0 & + \\
\hline Carbon content & -- & -- & 0 & -- & + & -- & 0 & + \\
\hline Heavy metal content & 0 & 0 & 0 & 0 & 0 & 0 & 0 & \\
\hline Organic pollutants & 0 & 0 & 0 & 0 & 0 & 0 & 0 & 0 \\
\hline Earthworm biomass & 0 & 0 & 0 & - & - & - & - & 0 \\
\hline Microbial biomass & - & -- & 0 & - & 0 & - & 0 & + \\
\hline Microbial activity & - & -- & 0 & - & 0 & - & 0 & + \\
\hline
\end{tabular}


earthworm activity in SALCA-SQ, assuming earthworm activity as a function of the course of soil temperature and moisture during the year. On the other hand, SALCA-SQ did not predict any differential effects of climate conditions for crop rotation $\mathrm{CR} 3$, or a combined effect of fertilisation system 3 on carbon content and, as a consequence, positive effects on aggregate stability and soil microorganisms.

The application of SALCA-SQ to different treatments in the field experiment (DOC) as a case study and to generic inventories as plausibility tests demonstrated the importance of having a method that assesses agricultural management impacts on soil quality in detail. A simple indicator based on land use intensity could not reveal any effects on different aspects of soil quality, nor differentiate between the effects of individual management practices. Since SALCA-SQ analyses all major types of impact classes, it can give a refined picture of the potential effects of agricultural management practices on different aspects of soil quality.

However, it has to be kept in mind that SALCA-SQ assesses the effects of management practices under standard conditions of climate and soil during field operations, considering as much as possible site-specific characteristics identifiable in the inventory data. Furthermore, assessments of SALCA-SQ are based on the assumption of 'standard farmer competence': Because a highly competent farmer may conserve or improve soil quality even under difficult conditions, i.e. by optimal timing of field operations, negative effects of agricultural management on soil quality predicted by SALCA-SQ do not necessarily materialise in reality. The same holds for positive assessments in situations with deficient farmer competence. The results of the plausibility tests with generic inventories demonstrate the complexity and interactions between effects of impact classes on indicators and site conditions. With mineral fertiliser, SALCA-SQ predicted negative effects for all crop rotations and with heavy machinery effects for both standard and wet climate conditions, but fertiliser system 3 gave overall positive effects. SALCA-SQ results for fertiliser system 2 also differed between the three crop rotations, as well as between standard and wet climate conditions in crop rotation 2 . The main factors in these examples were organic matter input, structure stabilisation by crops and wheeling for different management practices under changing conditions. Obviously, these examples and all the intermediate scenarios do not fully prove the validity of the method, but they allow a balance to be found for effects of different factors on management practice, impact class or indicator level.

Furthermore, concerning the results of DOC trial, SALCASQ overestimated positive effects on the organic carbon indicator; the predicted positive effects on organic carbon content could indeed be seen as relative differences between treatments, but not as changes in absolute soil organic carbon content. A possible explanation for this observation could be the humus balance method implemented in SALCA-SQ, which in the current version does not consider the initial humus content of soils, effective crop yields or the different effects of composted, rotted or stacked manure. Furthermore, on the small experimental plots of the DOC field trial, standard field machinery could not be used, and this may have prevented soil compaction and led to enhanced soil organic matter decomposition. In this respect, SALCA-SQ results matched our expectations of the soil quality impacts of these farming systems (increasing carbon content in organically fertilised treatment with ley in crop rotation), but the results measured in the DOC field trial situation did not confirm this. More refined modelling of the effects of input classes on soil quality indicators together with more thorough testing is necessary to demonstrate the validity of the impact class modelling in SALCA-SQ. However, by comparing SALCA-SQ assessments with field measurements, there is always the fundamental constraint that SALCA-SQ aims to predict standard effects and potential risks. This means that specific details of site conditions or management activities cannot be considered by SALCA-SQ because this type of information is normally not available from farm inventories. Therefore, SALCA-SQ will not exactly reproduce observed effects in all situations: The actual site conditions during a given field operation, e.g. with respect to soil moisture, soil structure, weather conditions or timeliness of the operation, are generally not known and are therefore accounted for in a standardised way assuming typical values. The same holds for the professional competence of a farmer, which is not known and cannot be accounted for.

The SALCA-SQ results obtained from application of the model to data from a single field trial (DOC trial), which are presented here as a case study, are in no way sufficient to judge the validity of the assessments made by SALCA-SQ. Therefore, broader validation is necessary, including the application of SALCA-SQ to data from a number of longterm field trials and a high number of data sets from real farms that vary in terms of site conditions, soil use and management practices. As a first step, SALCA-SQ was tested in the presented plausibility test, containing scenarios covering several key input classes (in this case crop rotation, type of machinery, soil type and climate combinations) with a broad range of characteristics.

In addition to the two examples presented here for the validation of SALCA-SQ, several field experiments in Switzerland (Nemecek et al. 2010a, b) and neighbouring countries (Deytieux et al., personal communication) have been modelled with SALCA-SQ and the assessments obtained compared against direct measurements of soil properties in field plots. The results of these applications of SALCA-SQ principally support the suitability and the usefulness of the method.

SALCA-SQ was developed taking into account the soil and climate conditions of Switzerland. Therefore, it has to 
be adapted for application in regions with considerably different site conditions, soil uses and management practices. Because of the modular and transparent design of SALCA-SQ, its methodological concept can be adapted and expanded to other site and management combinations, and its calculation factors can also be easily adapted. For example, estimation of the soil compaction risk includes a table where typical soil moisture is indicated depending on date, climate and soil type. A similar table exists for estimating the sensitivity of earthworms to damage by intensive soil tillage, depending on earthworm activity phases. These tables can easily be adapted to regional site conditions different to standard Swiss conditions, if the necessary data are available.

\section{Conclusions and recommendations}

SALCA-SQ assesses the impact of agricultural activities at farm level on soil quality indicators at farm level. In principle, this study demonstrated the applicability of the method using several case studies and plausibility tests. However, further research efforts are necessary to refine the assessment routines for the soil quality indicators based on new scientific knowledge, which is easily feasible due to the modular structure of SALCA-SQ. Another subject for further development is to reduce the number of indicators (and thus the data requirement) without losing prediction accuracy. This would make it easier to include SALCA-SQ results in LCIAs and to interpret them.

Collaboration between soil scientists and specialists in LCA is very fruitful for the development of a scientifically based impact assessment method such as SALCA-SQ that strikes a fine balance between complexity and practicability in the framework of LCIA. In particular, the inventory data should be collectable and reliable with adequate effort, which is the case for SALCA-SQ. Many of the data required by SALCA-SQ have already been collected by European farmers documenting their management activities to meet European Union standards on cross-compliance. Based on comprehensive inventory data, detailed predictions on the impacts of management activities on different aspects of soil quality are possible. Therefore, SALCA-SQ is a useful tool not only for LCIA but also for agricultural advisors and farmers analysing current management activities and aiming to make soil management more sustainable by better adapting it to the site conditions.

Acknowledgements The authors wish to thank Thomas Nemecek and Olivier Huguenin-Elie (both Agroscope Reckenholz-Tänikon ART) for preparing and calculating the data from the DOC experiment. We also thank the members of the working group which helped to develop the fundamentals of this method: Etienne Diserens, Andreas Fließbach, Christian Gysi, Jean-Auguste Neyroud and Ulrich Walther.

\section{References}

Audsley A, Alber S, Clift R, Cowell S, Crettaz P, Gaillard G, Hausheer J, Jolliet O, Kleijn R, Mortensen B, Pearce D, Roger E, Teulon H, Weidema B, van Zeijts H (1997) Report on Concerted action harmonisation of environmental life cycle assessment for agriculture. European Commission DG VI Agriculture, England, $140 \mathrm{pp}$

Benedetti A, Tittarelli F, Pinzari F, De Bertoldi S (2000) Proceedings of the joint WGs meeting of the cost action 831 biotechnology of soil: monitoring, conservation and remediation, 10-11 December 1998, Rome. European Communities, Luxembourg

Brentrup F (2003) Life cycle assessment to evaluate the environmental impact of arable crop production. Ph.D. Thesis. Cuvillier Verlag, Göttingen, $187 \mathrm{pp}$

Breure AM, Mulder C, Rutgers M, Schouten T, de Zwart D, Bloem J (2003) A biological indicator for soil quality. In: Francaviglia R (ed) Agricultural impacts on soil erosion and soil biodiversity: developing indicators for policy analysis, vol. 654. Proceedings from an OECD expert meeting, March 2003, Rome, Italy, pp. 485-494

Cowell SJ, Clift R (2000) A methodology for assessing soil quantity and quality in life cycle assessment. J Clean Prod 8:321-331. doi:10.1016/S0959-6526(00)00023-8

Doran JW, Parkin TB (1996) Quantitative indicators of soil quality: a minimum data sheet. In: Doran W, Jones AJ (eds) Methods for assessing soil quality. SSSA special publication 49. Soil Science Society of America, Inc., Madison, pp 25-38

EU Commission (2006) Strategy for soil protection-impact assessment of the thematic strategy on soil protection. Commission staff working document - document accompanying the communication from the Commission to the Council, The European Parliament, the European Economic and Social Committee and the Committee of the Regions. http://eur-lex.europa.eu/LexUriServ/LexUriServ.do? uri=CELEX:52006SC0620:EN:NOT

Fließbach A, Oberholzer H-R, Gunst L, Mäder P (2007) Soil organic matter and biological soil quality indicators after 21 years of organic and conventional farming. Agric Ecosyst Environ 118:273-284. doi:10.1016/j.agee.2006.05.022

Freiermuth R (2006) Modell zur Berechnung der Schwermetallflüsse in der Landwirtschaftlichen Ökobilanz. Agroscope FAL Reckenholz, 42 p. http://www.agroscope.admin.ch/oekobilanzen/01194/

Gaillard G, Nemecek T (2009) Swiss Agricultural Life Cycle Assessment (SALCA): an integrated environmental assessment concept for agriculture. International Conference on Integrated Assessment of Agriculture and Sustainable Development, Setting the Agenda for Science and Policy, AgSAP Office, Wageningen University, Egmond aan Zee, The Netherlands

Guinée J, van Oers L, de Koning A, Tamis W (2006) Life cycle approaches for conservation agriculture. Leiden University, Leiden, CML Report 171

Harris RF, Karlen DL, Mulla DJ (1996) A conceptual framework for assessment and management of soil quality and health. In: Doran JW, Jones AJ (eds) Methods for assessing soil quality. SSSA special publication 49. Soil Science Society of America, Inc., Madison, pp 61-82

ISO (2006) ISO 14044 environmental management-life cycle assessment-principles and framework, Geneva

Jolliet O, Müller-Wenk R, Bare J, Brent A, Goedkoop M, Heijungs R, Itsubo N, Peña C, Pennington D, Potting J, Rebitzer G, Stewart M, Udo de Haes H, Weidema B (2004) The LCIA midpointdamage framework of the UNEP/SETAC life cycle initiative. Int J LCA 9:394-404. doi:10.1007/BF02979083

Jossi W, Zihlmann U, Pfiffner L, Dubois D (2007) DOK-Versuch: Anbausystemeffekte auf die Regenwürmer. Agrarforschung 14 (2):66-71 
Karlen DL, Mausbach MJ, Doran JW, Cline RG, Harris RF, Schumann GE (1997) Soil quality: a concept, definition, and framework for evaluation. Soil Sci Soc Am J 61:4-10. doi:10.2136/ sssaj1997.03615995006100010001x

Karlen DL, Gardner JC, Rosek MJ (1998) A soil quality framework for evaluating the impact of CRP. J Prod Agric 11:56-60

Milà i Canals L (2003) Contributions to LCA methodology for agricultural systems. Site-dependency and soil degradation impact assessment. Ph.D. Thesis. Universitat Autonomia de Barcelona, Barcelona

Milà i Canals L, Bauer C, Depestele J, Dubreuil A, Freiermuth Knuchel R, Gaillard G, Michelsen O, Müller-Wenk R, Rydgren B (2006) Key elements in a framework for land use impact assessment. Int J LCA 12:5-15. doi:10.1065/lca2006.05.250

Nemecek T, Huguenin-Elie O, Dubois D, Gaillard G (2010a) Life cycle assessment of Swiss farming systems: I. Integrated and organic farming. doi:10.1016/j.agsy.2010.10.002

Nemecek T, Huguenin-Elie O, Dubois D, Gaillard G (2010b) Life cycle assessment of Swiss farming systems: II. Extensive and intensive production. Agr Syst. doi:10.1016/j.agsy.2010.07.007

Nielsen MN, Winding A (2002) Microorganisms as indicators of soil health. NERI Technical Report No. 388, National Environmental Research Institute, Copenhagen Ministry of the Environment, Copenhagen

Nortcliff S (2002) Standardisation of soil quality attributes. Agric Ecosyst Environ 88:161-168. doi:10.1016/S0167-8809(01)00253-5

Oberholzer H-R, Höper H (2007) Soil quality assessment and long-term field observation with emphasis on biological soil characteristics. In:
Benckisen G, Schnell S (eds) Biodiversity in agricultural production systems. CRC Press, Boca Raton, pp 399-423

Oberholzer H-R, Fliessbach A, Mäder P, Mayer J (2009) Einfluss biologischer und konventioneller Bewirtschaftung auf biologische Bodenqualitätsparameter: Entwicklungen im DOK Langzeitversuch nach $\mathrm{pH}$-Regulierung. Wissenschaftstagung für ökologischen Landbau, Zürich. http://orgprints.org/view/projects/ int conf_2009_wita.html

OIS (1998) Verordnung über Belastungen des Bodens (VBBo). EMDZ, Bern; (SR 814.12), 12 p

Peters J, Garcia Quijan J, Content T, Van Wyk G, Holden NM, Ward SM, Muys B (2003) A new land use impact assessment method for LCA: theoretical fundaments and field validation. In: 4th international conference on life cycle assessment in the agrifood sector, 6-8 Oct, Bygholm, Denmark. Working Papers. Ministry of Food, Agriculture and Fisheries, Danish Institute of Agricultural Sciences, pp 154-171

Schjønning P, Elmholt S, Christensen BT (2004) Soil quality management-concepts and terms. In: Schjønning P, Elmholt S, Christensen BT (eds) Managing soil quality: challenges in modern agriculture. CABI Publishing, Cambridge

Udo de Haes H, Finnveden G, Goedenkoop M, Hauschild M, Hertwich E, Hofstetter P, Jolliet O, Klöpffer W, Krewitt W, Lindeijer E, Müller-Wenk R, Olsen S, Pennington D, Potting J, Steen B (2002) Life-cycle impact assessment: striving towards best practice. Society of Environmental Toxicology and Chemistry (SETAC), Pensacola 